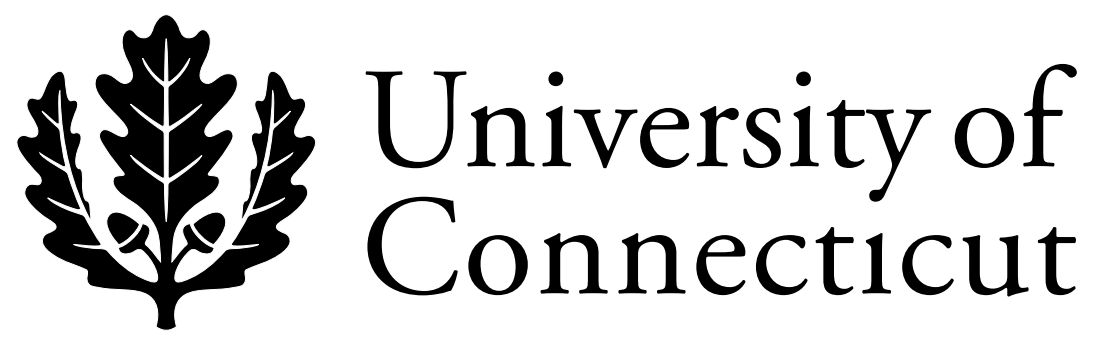

Department of Economics Working Paper Series

Voluntary Approaches to Nonpoint Pollution Control: Inducing First-best Outcomes through the Use of Threats

Kathleen Segerson

University of Connecticut

JunJie Wu

Oregon State University

Working Paper 2003-03

January 2003

341 Mansfield Road, Unit 1063

Storrs, CT 06269-1063

Phone: (860) 486-3022

Fax: (860) 486-4463

http://www.econ.uconn.edu/ 


\begin{abstract}
In this paper we develop a simple economic model to analyze the use of a policy that combines a voluntary approach to controlling nonpoint-source pollution with a background threat of an ambient tax if the voluntary approach is unsuccessful in meeting a pre-specified environmental goal. We first consider the case where the policy is applied to a single farmer, and then extend the analysis to the case where the policy is applied to a group of farmers. We show that in either case such a policy can induce cost-minimizing abatement without the need for farm-specific information. In this sense, the combined policy approach is not only more effective in protecting environmental quality than a pure voluntary approach (which does not ensure that water quality goals are met) but also less costly than a pure ambient tax approach (since it entails lower information costs). However, when the policy is applied to a group of farmers, we show that there is a potential tradeoff in the design of the policy. In this context, lowering the cutoff level of pollution used for determining total tax payments increases the likely effectiveness of the combined approach but also increases the potential for free riding. By setting the cutoff level equal to the target level of pollution, the regulator can eliminate free riding and ensure that cost-minimizing abatement is the unique Nash equilibrium under which the target is met voluntarily. However, this cutoff level also ensures that zero voluntary abatement is a Nash equilibrium. In addition, with this cutoff level the equilibrium under which the target is met voluntarily will not strictly dominate the equilibrium under which it is not. We show that all results still hold if the background threat instead takes the form of reducing government subsidies if a pre-specified environmental goal is not met.
\end{abstract}

Keywords: ambient taxes, nonpoint-source pollution control, cost-minimizing abatement, voluntary approach 


\section{Voluntary Approaches to Nonpoint Pollution Control: Inducing First-best Outcomes through the Use of Threats}

\section{INTRODUCTION}

While concerns about pollution control originally focused on point sources of pollution, attention has now turned to the control of diffuse or nonpoint-source pollution (NPP). ${ }^{1}$ Control of NPP is hampered by the fact that emissions of pollutants are not readily observable given their diffuse nature, which implies that traditional policy instruments based on emissions (e.g., emissions taxes or regulation) cannot be used in this context. This has lead economists to consider alternative policy instruments for the control of NPP, including input taxes, input regulations, ambient taxes, random fines, and type-specific contracts (Griffin and Bromley 1982; Shortle and Dunn 1986; Segerson 1988, Xepapadeas 1991, 1992, 1995; Cabe and Herriges 1992; Herriges et al. 1994; Govindasamy et al. 1994; and Shortle and Abler 1994). Instruments that provide flexible incentives (such as ambient taxes) can be used to induce first-best control of NPP (Segerson 1988), but information about farm-level charactertistics is needed to design these first-best policy instruments. They have thus been criticized as being likely to involve high information and/or transactions costs (e.g., Cabe and Herriges 1992; Batie and Ervin 1997). This has led some to suggest the use of second best policy instruments instead (Helfand and House 1995; Wu and Babcock 1995, 1996; Wu, et al. 1995). Use of these second best instruments involves a tradeoff. While transaction and information costs may be lower, these instruments do not achieve the targeted water quality level at the minimum abatement cost.

In contrast to the theoretical literature of NPP, water quality policy has historically been based on the use of "carrot" instruments designed to entice farmers to use environmentallyfriendly practices voluntarily or to participate in voluntary programs aimed at improving water 
quality. ${ }^{2}$ However, the varying success rates of voluntary programs have led some to question whether reliance on voluntary measures alone will adequately control agricultural pollution (Ribaudo and Caswell 1997), suggesting the need for mandatory controls or incentives to ensure adequate environmental protection. Yet, as noted above, mandatory controls ${ }^{3}$ generally have drawbacks in terms of inflexibility (in the case of second-best instruments) or high transaction or information costs (for first-best instruments). Thus, neither purely voluntary programs nor mandatory approaches by themselves seem to offer a desirable "solution" to agricultural NPP.

There is, however, an alternative role for voluntary and mandatory approaches to NPP, namely, as complementary instruments to be used together rather than as substitutes to be used in isolation. As has become apparent in the context of point source pollution, the threat of the imposition of mandatory controls can be an effective mechanism for inducing firms to participate in voluntary agreements (Segerson and Miceli 1998), while voluntary approaches have the potential to provide greater flexibility in meeting environmental quality goals and hence lower compliance and transaction costs (Commission of the European Communities 1996).

A few states have experimented with the use of mandatory approaches as threats to be invoked if reliance on voluntary measures is insufficient to control nonpoint source pollution, and the threat of regulation has been shown to create an incentive for farmers to alter their production practices (Ribaudo and Caswell 1997). Yet to date the economic literature on NPP has not considered the possible use of both voluntary and mandatory approaches as complementary parts of a policy package. Segerson and Miceli (1998) develop a model of this type in the context of point source pollution, where the regulator negotiates with an individual firm (or an industry representative) over the level of abatement under the agreement. Their focus is on the negotiated level of abatement that emerges under the agreement. They do not consider 
an approach under which the regulator sets an environmental quality target and then seeks participation in a program to achieve that target, as is typical in the case of NPP. Dawson and Segerson (2002) examine the use of industry-wide threats to induce participation in voluntary approaches, but again the context is point source pollution where the threat is an emissions tax (a policy instrument that is not feasible in the context of NPP). Wu and Babcock (1999) compare the relative efficiency of voluntary and mandatory approaches to NPP, but they treat the two as alternatives and do not consider a policy package under which the two are combined.

In this paper we develop a simple economic model to analyze the use of a policy that combines a voluntary approach to controlling nonpoint-source pollution with a background threat of an ambient tax (or losing government subsidies) if the voluntary approach is unsuccessful in meeting a pre-specified environmental goal. We use the model to examine whether the regulator can use such a policy to solve free-rider problems and to induce costminimizing abatement decisions without the need for farm-specific information about pollutionrelated characteristics. We first consider how a single farmer would respond to such a combined policy. We consider both a static model, in which imposition of the threat can occur instantaneously when the target is not met, and a dynamic model, in which there is a lag between failure to meet the goal and imposition of the threat. We then extend the analysis to the case where the policy is applied to a group of farms. In this context, we ask whether cost-minimizing abatement decisions are a Nash equilibrium.

We show that, in both the case where the policy is applied to a single farmer and where it is applied to a group of farmers, such a policy can induce cost-minimizing abatement without the need for farm-specific information. In this sense, the combined approach can be both more effective than a purely voluntary approach and involve lower information or transaction costs 
than a pure tax approach. However, when the policy is applied to a group of farmers, we show that there is a potential tradeoff in the design of the policy. Lowering the cutoff level of pollution used for determining total tax payments increases the likely effectiveness of the combined approach but, when applied to a group of farmers, it also increases the potential for free riding. While the cutoff level can be set to eliminate free riding and ensure that costminimizing abatement is a unique Nash equilibrium under which the target is met voluntarily, this level will also make the farmers indifferent between meeting the target voluntarily and facing the ambient tax. While we derive the results assuming the regulator threatens imposition of an ambient tax, all of our results still hold if the background threat instead takes the form of reducing government subsidies if a pre-specified environmental goal is not met.

\section{SINGLE POLLUTER CASE}

We consider first the case of a single farmer whose agricultural activities pollute a nearby waterbody. The farmer can engage in abatement practices, such as the use of reduced tillage, establishment of buffer strips, construction of manure storage facilities, and land retirement, to reduce water pollution, or, equivalently, to increase ambient water quality in the waterbody. Expected ambient pollution in the waterbody, denoted $x$, is a function of the farmer's pollution abatement practices, denoted $a=\left(a^{1}, a^{2}, \ldots, a^{m}\right)$, and the physical characteristics of the farm (e.g., the steepness of the fields and/or the proximity to the waterbody), denoted $\theta$. Thus, $x=x(a, \theta)$, where $\partial x / \partial a^{i} \leq 0$ and $\partial x / \partial \theta \geq 0 .{ }^{4}$ We assume that, although each farmer knows his or her own $\theta$, the regulator knows only the distribution of $\theta$. The cost of abatement, denoted $C$, depends on both the abatement efforts and the physical characteristics of the farm, i.e., $C=C(a, \theta)$, where $\partial C / \partial a^{i} \geq 0$ for all $i$. For example, the cost of establishing riparian buffer strips 
depends not only on the establishment cost (e.g., fencing cost) but also on the land quality, which determines the opportunity cost of the land taken out of production. ${ }^{5}$

We assume that there is some exogenously set target level of water quality determined by a criterion such as "fishable and swimmable" or by the level necessary to support some desirable activity (e.g., salmon spawning). This requires that ambient pollution not exceed an exogenous standard, $x_{s}$. The regulator takes this standard as given and tries to design a policy to ensure that this standard is met at least cost. ${ }^{6}$ A good example is the Total Maximum Daily Loads (TMDLs), mandated by Section 303(d) of the Clean Water Act. A TMDL is a water quality standard that establishes the maximum amount of pollution that a watershed can assimilate without violating state water quality standards.

The cost-minimizing abatement vector, denoted $a^{*}=a^{*}\left(x_{s}, \theta\right)$, solves

$$
\begin{array}{cl}
\text { minimize } & C(a, \theta) \\
\text { subject to } & x(a, \theta) \leq x_{s} . \\
& a \geq 0 .
\end{array}
$$

The necessary first-order conditions require that at $a^{*}\left(x_{s}, \theta\right)$ :

$$
\partial C / \partial a^{i}+\lambda *\left(x_{s}, \theta\right) \partial x / \partial a^{i} \geq 0
$$

where $\lambda *\left(x_{s}, \theta\right)$ is the optimal value of the Lagrangian multiplier. These conditions are also sufficient, under the appropriate curvature assumptions. Then $C^{*} \equiv C^{*}\left(x_{s}, \theta\right)=C\left(a^{*}\left(x_{s}, \theta\right), \theta\right)$ is the minimum cost of meeting the standard, where $\partial C * / \partial x_{s}<0$.

We consider the following policy scenario. The regulator agrees to give the farmer a chance to meet the standard voluntarily. If the standard is met, no further policy is imposed. However, if the standard is not met, the regulator will impose an ambient tax, with the magnitude of the tax set at the level sufficient to induce the farmer to choose an abatement vector that 
ensures that the standard will be met. Imposition of the tax requires that the regulator spend the resources necessary to learn $\theta$, since the magnitude of the tax necessary to ensure that the target is met depends on $\theta$. However, since the farmer knows his own $\theta$, he can anticipate the magnitude of the tax that the regulator will impose if the voluntary approach fails. In this section we assume that the regulator can instantaneously observe whether the standard has been met and impose the tax if necessary. In Section III, we consider an extended dynamic model in which imposition of a tax follows in a subsequent period.

Formally, under the above policy, the farmer faces the following policy-related costs:

$$
T= \begin{cases}0 & \text { if } x\left(a_{v}, \theta\right) \leq x_{s} \\ t\left(x\left(a_{t}, \theta\right)-\bar{x}\right) & \text { if } x\left(a_{v}, \theta\right)>x_{s}\end{cases}
$$

where $a_{v}$ is the announced or intended abatement vector under the voluntary program, $a_{t}$ is the abatement vector that is chosen if the tax is imposed, $t$ is the ambient tax rate, and $\overline{\mathrm{x}} \leq x_{s}$ is a "cutoff level" of pollution. ${ }^{7}$ Note that this policy is analytically similar to the pure ambient tax/subsidy policy considered in Segerson (1988). ${ }^{8}$ Under both policies, if ambient pollution exceeds a given target, a tax is imposed on the amount by which the ambient level exceeds a given cutoff level. However, in Segerson (1988), the target level $\left(\mathrm{x}_{\mathrm{s}}\right)$ and the cutoff level $(\bar{x})$ are the same. Under the voluntary approach proposed here, we allow the two to differ. The importance of this is discussed in detail below. Another difference between the two policies arises when pollution is below the target. The voluntary approach acts like a pure tax policy, in that the farmer receives (and pays) nothing when the target is met, i.e., when ambient pollution is at or below the target level. In contrast, under the ambient tax/subsidy policy, the farmer receives a subsidy proportional to the amount by which pollution is below the target. ${ }^{9}$ 
We begin by establishing that, when facing the above policy, meeting the standard in the least cost way is an optimal response for the farmer.

PROPOSITION 1: If $t=\lambda *\left(x_{s}, \theta\right)$, then $(i)$ the cost-minimizing abatement vector is an optimal voluntary abatement vector, i.e., $a^{*} \in \operatorname{argmin} C_{v}$, where $C_{v}$ is the farmer's cost under the above policy. Furthermore, (ii) if $\bar{x}<x_{s}$, then $a^{*}$ is the unique optimal voluntary abatement vector, while if $\bar{x}=x_{s}$, then $0 \in$ argmin $C_{v}$ as well. (iii) The pollution standard will be met at minimum cost for any $\bar{x}$.

PROOF: The farmer's choice of $a_{v}$ determines whether or not the tax is imposed. Faced with the tax, the farmer will choose $a_{t}$ to minimize $C\left(a_{t}, \theta\right)+t\left(x\left(a_{t}, \theta\right)-\bar{x}\right)$. The first-order conditions is then

$$
\partial C / \partial a^{i}+t \cdot \partial x / \partial a^{i} \geq 0
$$

If $t=\lambda *\left(x_{s}, \theta\right)$, the solution is $a_{t}^{*}=a^{*}\left(x_{s}, \theta\right)$, and the corresponding total cost is $C^{*}+t \cdot\left(x_{s}-\bar{x}\right)$.

Given this, when choosing $a_{v}$, the farmer faces the following costs:

$$
C_{v}= \begin{cases}C\left(a_{v}, \theta\right) & \text { if } x\left(a_{v}, \theta\right) \leq x_{s} \\ C^{*}+t\left(x_{s}-\bar{x}\right) & \text { if } x\left(a_{v}, \theta\right)>x_{s}\end{cases}
$$

The results in the proposition then follow directly.

Proposition 1 implies that the combined policy can induce cost-minimizing voluntary abatement regardless of the level of $\bar{x}$. If $\bar{x}<x_{s}$, the farmer will strictly prefer to meet the standard voluntarily (at minimum cost), while if $\bar{x}=x_{s}$, he will be indifferent between meeting it voluntarily and choosing an abatement vector that triggers the tax. 
Figure 1 illustrates the results in Proposition 1 for the case where $a$ is a scalar and $\bar{x}<x_{s}$. The dashed curve is the cost function that the farmer faces under the combined policy. If the farmer's abatement level is greater than or equal to $a^{*}$, he will face no tax, and the farmer's total cost is simply $C\left(a_{v}, \theta\right)$. However, if his abatement level is lower then $a^{*}$, the standard will not be met voluntarily, and a tax will be imposed. If $t=\lambda *\left(x_{s}, \theta\right)$, the farmer will choose the costminimizing abatement level and his total cost is then $C^{*}+t \cdot\left(x_{s}-\bar{x}\right)$. It is clear from Figure 1 that over the entire domain the farmer's total costs are minimized at $a^{*}$. Note that the discontinuity in the farmer's total costs stems from the assumption that $\bar{x}<x_{s}$. If $\bar{x}=x_{s}$, the discontinuity is eliminated. Even without this discontinuity, the farmer's total cost is still minimized (although not uniquely) at $a^{*}$. Thus, the cost-minimizing abatement level minimizes the farmer's cost regardless of the value of $\bar{x}$.

Proposition 1 shows that for any cutoff level the standard will be met at minimum cost. However, this does not mean that the choice of $\bar{x}$ is unimportant. In Segerson (1988), the cutoff level of pollution $\bar{x}$ was one key parameter that the regulator could choose to ensure efficient exit/entry conditions and industry size. Here it plays a very different role. Although in equilibrium the water quality target can be met at minimum cost for any $\bar{x}$, when $\overline{\mathrm{x}}<x_{s}$, the farmer's cost if he meets the target voluntarily will be strictly lower than his cost if he meets it only after the tax has been imposed. The farmer's total cost under the tax serves as a reservation cost that defines a maximum amount of abatement (if abatement is a scalar) or an abatement vector that the farmer would be willing to undertake voluntarily, $a^{\max }$, given by

$$
C\left(a^{\max }, \theta\right) \equiv C^{*}+t \cdot\left(x_{s}-\bar{x}\right) .
$$

Note that in the scalar case $a^{\max }>a^{*}$, i.e., the maximum amount of abatement the farmer would be willing to undertake voluntarily exceeds the cost-minimizing level if $x_{s}>\bar{x}$. Thus, while the 
farmer's optimal choice is still $a^{*}$, when $\bar{x}<x_{s}$ the farmer would actually be willing to undertake more abatement to avoid payment of the tax. ${ }^{10}$

However, if the regulator sets $\bar{x}=x_{s}$, the farmer's costs are not strictly lower if the standard is met voluntarily (i.e., the discontinuity in Figure 1 is eliminated) and in the scalar case $a^{\max }=a^{*}$. In this case, the farmer is indifferent between meeting the standard voluntarily and having the tax imposed, and has no incentive to undertake more abatement voluntarily than he would undertake if he had to pay the tax. In other words, the tax is no longer a real threat to the farmer, since it imposes no costs above and beyond what he would incur if he met the target voluntarily.

In sum, in the single farmer case, combining the voluntary approach and the ambient tax (i.e., treating them as complements in a policy package rather than as substitute policies) can ensure that the target is met at minimum cost without incurring the potentially high information costs necessary for imposing an ambient tax. If $\bar{x}<x_{s}$, this is the unique equilibrium outcome under the combined policy. In this case, the tax is never actually imposed because the threat of imposition of the tax is sufficient to induce voluntary compliance. As a result, the regulator does not need to incur the costs of learning $\theta$. Thus, the combined policy approach is not only more effective in protecting environmental quality than a pure voluntary approach (which does not ensure that water quality goals are met) but also less costly than a pure ambient tax approach (since it entails lower information costs). If $\bar{x}=x_{s}$, cost-minimizing voluntary abatement is still an equilibrium outcome, but the farmer no longer strictly prefers this to the outcome under which the tax is imposed. This suggests that in designing the policy, the regulator should set $\bar{x}<x_{s}$. We show below that this conclusion continues to hold when the single farmer model is extended to incorporate a more explicit and realistic timing of possible imposition of the tax. However, 
we show that, when extended to apply to a group of farmers, setting $\bar{x}<x_{s}$ can induce an allocation inefficiency.

\section{AN EXTENSION TO A DYNAMIC MODEL}

The above model assumes that the regulator can observe instantaneously whether the target has been met voluntarily and immediately impose the tax if it has not. In this section, we present an extended model that incorporates a more explicit and realistic timing of events. We show that, when $\bar{x}<x_{s}$, the result from the static model presented in the previous section continues to hold in this context, provided the discount rate is sufficiently low relative to the difference between $x_{s}$ and $\bar{x} .{ }^{11}$ However, when $\bar{x}=x_{s}$, the farmer will strictly prefer not to meet the standard voluntarily. This is in contrast to the result in the static model, where the farmer was indifferent between meeting it voluntarily and facing the tax when $\bar{x}=x_{s}$.

We view the problem as an infinitely repeated game between the regulator and the farmer. During each time period the farmer chooses an abatement level, which determines whether or not the standard will be met in that period. There is no "carry over" effect of pollution abatement. At the end of each period, the regulator observes whether the standard has been met during that period. The regulator then plays the following trigger strategy. No tax is imposed during the first period. If during that period the regulator observes that the water quality standard has been met voluntarily, she does not impose any tax in the following period and the game is repeated. However, if during that period (or any subsequent period in which a tax has not been imposed) she observes that the standard has not been met voluntarily, then she expends the resources necessary to learn $\theta$ and imposes a tax equal to $\lambda^{*}\left(\mathrm{x}_{\mathrm{s}}, \theta\right)$ for all of the remaining periods. 
Consider the farmer's first-period choice. If the farmer chooses not to meet the target voluntarily in the first period, then the present value of the stream of total costs will be

$$
\left[C^{*}+t \cdot\left(x_{s}-\bar{x}\right)\right] \cdot\left(\delta+\delta^{2}+\delta^{3}+\ldots\right)=\left[C^{*}+t \cdot\left(x_{s}-\bar{x}\right)\right] \cdot[\delta /(1-\delta)],
$$

where $\delta=1 /(1+r)$ is the discount factor and $r$ is the discount rate. Suppose instead the farmer chooses to meet the target voluntarily in the first period, with the corresponding $\operatorname{cost}$ of $C^{*}$. Then the regulator will not impose the tax, and at the beginning of the second period the farmer will face the same decision (and possible payoffs) that he faced at the beginning of the first period. If meeting the target is optimal for the first period, then it will be optimal for the second period and all subsequent periods as well. Let $V$ denote the present value of the infinite stream of costs incurred from making this choice optimally now and every time it arises in the future. Then

$$
V=C^{*}+\delta V,
$$

which implies that

$$
V=C^{*} /(1-\delta)=C^{*} \cdot\left(1+\delta+\delta^{2}+\ldots\right) .
$$

Comparing the present values in (5) and (7) yields the following result.

PROPOSITION 2: Suppose the regulator employs a trigger strategy whereby he does not impose an ambient tax initially and then imposes a (permanent) ambient tax in period $T$ if and only if the water quality target was not met in period T-1. Then the farmer's optimal response is to meet the target voluntarily in each period if and only if $r<t \cdot\left(x_{s}-\bar{x}\right) / C^{*}$.

Proposition 2 states that meeting the target voluntarily will be optimal for the farmer if and only if the discount rate is sufficiently low. Rewriting this condition as $C^{*}<t\left(x_{\mathrm{s}^{-}} \bar{x}\right) / r$ 
provides the intuition for this result: the farmer will meet the target voluntarily provided the gain from avoiding abatement in the first period $C^{*}$ is less than the present value of the stream of tax payments the farmer would incur by triggering imposition of the tax $\left(t\left(x_{\mathrm{s}^{-}} \bar{x}\right) / r\right)$. Clearly, this condition will never be met for any positive discount rate if $\bar{x}=x_{s}$. In this case, even if the tax is subsequently imposed in response to failure to meet the target in the previous period, as long as the target is subsequently met, there will be no net tax payments under the tax. Thus, even under the trigger strategy, with $\bar{x}=x_{s}$ the farmer is effectively given a new opportunity to meet the standard in each period. This eliminates any opportunity to "punish" the farmer for failure to meet the standard in a previous period. Thus, with $\bar{x}=x_{s}$ it is optimal for the farmer to take advantage of the first period reprieve and then meet the standard in all subsequent periods, regardless of his discount rate. This follows provided that the tax is based on ambient pollution in the period in which it is imposed. If the tax is based on the ambient pollution in the previous period, i.e., if it is applied retroactively, the regulator would have the ability to punish firstperiod non-compliance. Note that if the regulator had not offered the voluntary approach but had instead simply imposed an ambient tax in all periods, farmers would faced net tax payments for any period in which the target was not met. In this sense, if $\bar{x}=x_{s}$, use of a pure ambient tax would lead to greater environmental protection than use of the voluntary approach, which allows the farmer to postpone abatement for one period at no cost.

However, if $\bar{x}<x_{s}$, it is optimal for the farmer to meet the standard voluntarily in all periods, provided his discount rate is low enough. In this case, if the farmer fails to meet the standard voluntarily in a given period, he will face a positive tax payment in all future periods even if he subsequently meets the standard in all future periods. Thus, with $\bar{x}<x_{s}$, the farmer is not given a second chance to meet the target at no additional cost (i.e., no cost in addition to the 
cost of abatement). As a result, by setting $\bar{x}<x_{s}$ the regulator can induce voluntary compliance in all periods as long as the discount rate and/or $\bar{x}$ is sufficiently low. Thus, in contrast to the static model, in this dynamic context, cost-minimizing abatement is not an optimal voluntary abatement vector for all $\bar{x}$. Nonetheless, the results here confirm the result from the static model that the policy is more likely to induce voluntary cost-minimizing abatement if the regulator sets $\bar{x}<x_{s}$.

\section{MULTIPLE FARMERS}

While the single-farm case provides a benchmark for the study of the combined policy approach, in many contexts there are likely to be several farms whose activities contribute to ambient water pollution in a neighboring lake or stream. We show in this section that a voluntary program coupled with a background threat of an ambient tax can induce costminimizing abatement decisions in this context as well. More specifically, we show that under the appropriate design of the ambient tax cost-minimizing voluntary abatement by all farmers is a Nash equilibrium. However, consistent with the results from the static model of a single farmer, whether this equilibrium is unique or not depends on the relative magnitudes of $x_{s}$ and $\bar{x}$. In particular, we show that, when the policy is applied to a group of farmers, there is a fundamental tradeoff in setting the magnitudes of $x_{s}$ and $\bar{x}$ between creating incentives for voluntary abatement and inducing free-riding by some farmers.

In this extension of the model, we assume that there are $\mathrm{n}$ farms and each farmer knows his own type $\left(\theta_{\mathrm{j}}\right)$ and the other farmers' types. ${ }^{12}$ The expected ambient water pollution is then $x=x\left(a_{1}, a_{2}, \ldots, a_{n} ; \theta_{1}, \theta_{2}, \ldots, \theta_{n}\right)$. For simplicity, we assume that each farmer's abatement choice is a scalar, and that the regulator can observe instantaneously whether the target has been met 
voluntarily and immediately impose the tax if it has not. As before, the objective of the regulator is to meet an exogenously set water quality standard at minimum cost. The cost-minimizing abatement choices $\left\{a_{j}{ }^{*}\left(\theta_{1}, \theta_{2}, \ldots, \theta_{n}, x_{s}\right), j=1,2, \ldots, n\right\}$ solve $\mathrm{e}^{13}$

$$
\operatorname{minimize} C\left(a_{1}, \theta_{1}\right)+C\left(a_{2}, \theta_{2}\right)+\ldots+C\left(a_{n}, \theta_{n}\right)
$$$$
\text { subject to } x\left(a_{1}, a_{2}, \ldots, a_{\boldsymbol{n}} ; \theta_{1}, \theta_{2}, \ldots, \theta_{\boldsymbol{n}}\right) \leq x_{s} \text {. }
$$

The necessary first order conditions are

$$
\partial C / \partial a_{j}+\lambda *\left(x_{s}, \theta_{1}, \theta_{2}, \ldots, \theta_{n}\right) \cdot\left(\partial x / \partial a_{j}\right) \geq 0, \text { for all } j
$$

where $\lambda *\left(x_{s}, \theta_{1}, \theta_{2}, \ldots, \theta_{n}\right)$ is the optimal value of the Lagrangian multiplier. Let $C_{j}^{*} \equiv C\left(a_{j}{ }^{*}\left(\theta_{l}\right.\right.$, $\left.\left.\theta_{2}, \ldots, \theta_{\boldsymbol{n}}, x_{s}\right), \theta_{j}\right)$ be the corresponding abatement cost for farmer $j$.

As before, we assume that the regulator imposes an ambient tax if and only if the water quality target is not met voluntarily. All farmers with potential contributions to the waterbody would be subject to the tax. If the tax is imposed, each farmer chooses his abatement level to minimize $C\left(a_{j}, \theta_{j}\right)+t \cdot\left[x\left(a_{1}, a_{2}, \ldots, a_{\boldsymbol{n}} ; \theta_{1}, \theta_{2}, \ldots, \theta_{\boldsymbol{n}}\right)-\overline{\mathrm{x}}\right]$. If the regulator sets $t=\lambda *\left(x_{s}, \theta_{1}, \theta_{2}\right.$, $\left.\ldots, \theta_{n}\right)$, then under the tax each farmer will choose the cost-minimizing abatement level $a_{j}^{*}\left(\theta_{l}, \theta_{2}\right.$ $\left., \ldots, \theta_{\boldsymbol{n}}, x_{s}\right)$, if he believes that other farmers will do the same, i.e., cost-minimizing abatement is a Nash equilibrium under the ambient tax. ${ }^{14}$ The corresponding cost for farmer $j$ is then $C_{j}{ }^{*}+t \cdot\left(x_{s^{-}} \overline{\mathrm{x}}\right)$. This represents farmer $j$ 's reservation cost. Farmer $j$ will not voluntarily undertake abatement that generates costs in excess of $C_{j}{ }^{*}+t \cdot\left(x_{s^{-}} \overline{\mathrm{x}}\right)$; if costs under voluntary compliance exceed $C_{j}{ }^{*+t} \cdot\left(x_{s^{-}} \overline{\mathrm{x}}\right)$, the farmer would be better off if the target is not met and the ambient tax is imposed. This reservation cost thus defines a maximum amount of abatement that farmer $\mathrm{j}$ would be willing to undertake voluntarily, $a_{j}^{\max }$, given by

$$
C\left(a_{j}^{\max }, \theta_{j}\right) \equiv C_{j}^{*}+t \cdot\left(x_{s^{-}} \overline{\mathrm{x}}\right) .
$$


Note that $a_{j}^{\max }>a_{j}{ }^{*}\left(\theta_{1}, \theta_{2}, \ldots, \theta_{n}, x_{s}\right)$ if $x_{s}>\bar{x}$, i.e., the maximum amount of abatement farmer $j$ would be willing to undertake voluntarily exceeds the cost-minimizing level. From (11), it follows that

$$
\frac{\partial a_{j}^{\max }}{\partial \bar{x}}=-\frac{t}{C_{a_{j}}}<0
$$

This implies that an increase in the cutoff level of pollution will reduce the maximum amount of abatement each farmer is willing to undertake. Similarly, under the assumption that $C_{a_{j} a_{j}}<0$ and $x_{a_{j} a_{j}}<0$, we can show that

$$
\frac{\partial a_{j}^{\max }}{\partial x_{s}}=\frac{1}{C_{a_{j}}}\left(t+\frac{\partial a_{j}^{*}}{\partial x_{s}}\right)=\frac{1}{C_{a_{j}}}\left(t-\frac{x_{a_{j}} \lambda_{x_{s}}^{*}}{C_{a_{j} a_{j}}+\lambda^{*} x_{a_{j} a_{j}}}\right)>0,
$$

where $\lambda_{x_{s}}^{*}=\partial\left(C_{1}^{*}+\ldots+C_{n}^{*}\right) / \partial x_{s}<0$ and $x_{a_{j}}<0$. This implies that reducing the water quality standard would increase the maximum amount of abatement each farmer is willing to undertake voluntarily. With a lower water quality standard, the cost the farmer would face under the tax is greater. Thus, he is willing to undertake more voluntary abatement in order to avoid imposition of the tax.

We can now characterize the abatement levels that constitute Nash equilibria under a policy where the regulator imposes an ambient tax if and only if the water quality target is not met voluntarily.

Proposition 3: The abatement levels $\left(a_{1 v}, a_{2 v}, \ldots, a_{n v}\right)$ are a Nash equilibrium under which the water quality target is met voluntarily if and only if they satisfy

$$
\text { (i) } \quad a_{j v} \leq a_{j}^{\max } \text { for all } j \text {, and }
$$


(ii) $\quad x\left(a_{1 v}, a_{2 v}, \ldots, a_{n v} ; \theta_{1}, \theta_{2}, \ldots, \theta_{n}\right)=x_{s}$.

PROOF: By the definition of $a_{j}^{\max }$, as long as $a_{j v} \leq a_{j}^{\max }$, farmer $j$ would incur lower costs by choosing this abatement level than by facing the tax if this abatement level ensured that the water quality target is met voluntarily. Let $a_{-j}=\left(a_{1 v}, \ldots, a_{j-1 v}, a_{j+1 v}, \ldots, a_{n v}\right)$ be the voluntary abatement choices of all farmers other than farmer $j$. Suppose there exists an $a_{j v}\left(\right.$ denoted $\left.a_{j}{ }^{\prime}\right)$ such that $\left(a_{j}{ }^{\prime}, a_{-j}\right)$ satisfies (i) and (ii). Then $a_{j}{ }^{\prime}$ is a best response to $a_{-j}$. Clearly, farmer $j$ would not choose a level of abatement greater than this $a_{j}{ }^{\prime}$, since doing so would increase his cost. Similarly, choosing an abatement level lower than $a_{j}{ }^{\prime}$ would result in failure of the voluntary approach and imposition of the tax. Because $a_{j}{ }^{\prime} \leq a_{j}{ }^{\max }$, the cost from choosing $a_{j}{ }^{\prime}$ can be no higher than the cost from choosing any level of abatement that results in imposition of the tax. Hence, the farmer can do no better (and will possibly be worse off) by choosing any abatement level less than $a_{j}{ }^{\prime}$. Thus, any combination of $\left(a_{1 v}, a_{2 v}, \ldots, a_{n v}\right)$ satisfying (i) and (ii) is a Nash equilibrium. Conversely, any Nash equilibrium under which the water quality target is met voluntarily must satisfy (i) since otherwise some farmers would prefer the tax. It also must satisfy (ii) because if $x>x_{s}$, the water quality standard is not met; and if $x<x_{s}$, then given the abatement levels of all other farmers, some farmer could incur lower costs by reducing his abatement to the level where $x=x_{s}$. Q.E.D.

Because $\left\{a_{j}^{*}\left(\theta_{1}, \theta_{2}, \ldots, \theta_{n}, x_{s}\right), j=1,2, \ldots, n\right\}$ satisfies both conditions in Proposition 3, the following proposition follows immediately: 
Proposition 4: The cost-minimizing abatement levels $\left\{a_{j}^{*}\left(\theta_{1}, \theta_{2}, \ldots, \theta_{n}, x_{s}\right), j=1,2, \ldots, n\right\}$ are a Nash equilibrium under which the target is met voluntarily for any level of $\bar{x}$.

This result implies that under the voluntary approach it is optimal for each farmer to undertake the cost-minimizing abatement, as long as he believes other farmers are doing so. Thus, cost-minimizing abatement is a Nash equilibrium. In this case, as in the single farmer model, for any level of $\bar{x}$, by providing farmers the opportunity to meet the target voluntarily, the regulator can achieve cost-minimizing abatement without incurring the information costs that would be associated with reliance solely on an ambient tax.

In contrast to the result in the single farmer model, with multiple farmers costminimizing voluntary abatement is never a unique equilibrium. If $x_{s}>\overline{\mathrm{x}}$, there are other Nash equilibria under which the target is met voluntarily (but not at minimum cost). For example, in the case of two farms, as long as $x\left(0, a_{2}^{\max } ; \theta_{1}, \theta_{2}\right)=x_{s},\left(0, a_{2}^{\max }\right)$ is also a Nash equilibrium but it does not minimize the total abatement cost. In this case, farmer 2 would face a higher cost under the tax than he would incur by achieving the water quality standard by himself. Realizing this, farmer 1 would free ride on farmer 2's effort. Because of the free rider problem, aggregate abatement costs are higher than they would have been under a pure ambient tax, since the allocation of abatement across farms is inefficient. ${ }^{15}$

In addition, under some circumstances, zero voluntary abatement may also be a Nash equilibrium. 
PROPOSITION 5: Let $a_{j}^{s}$ be implicitly defined by $x\left(0, \ldots 0, a_{j}^{s}, 0, \ldots 0 ; \theta_{1}, \theta_{2}, \ldots \theta_{n}\right)=x_{s}$. Then zero voluntary abatement $\left(a_{1 v}=0, a_{2 v}=0, \ldots, a_{n v}=0\right)$ is a Nash equilibrium if $a_{j}^{s}>a_{j}^{\max }$ for $j=1,2, \ldots$, $n$.

Proposition 5 states that, if all farmers would incur higher costs by meeting the target on their own than they would incur under the ambient tax, i.e., if no farm is willing to meet the target on its own, then an outcome under which no farmer abates voluntarily is a Nash equilibrium. Thus, it is possible that in equilibrium the water quality target will not be met voluntarily and the ambient tax will be imposed. Note, however, that provided $\bar{x}<x_{s}$, the outcome under which each voluntarily chooses his cost-minimizing abatement $\mathrm{a}_{\mathrm{j}}{ }^{*}$ always strictly dominates the zero voluntary abatement equilibrium since it yields lower total costs for all farmers. Hence, if farmers are able to engage in "cheap talk," (see Rasmusen 1994) i.e., to communicate about their abatement plans (as would be expected in relatively small watersheds where farmers are neighbors), we would not expect the zero voluntary abatement outcome to emerge as the equilibrium when $\bar{x}<x_{s}$.

The above results suggest that when $\bar{x}<x_{s}$ there will be Nash equilibria under which the target is met voluntarily but not at least cost because of free-riding. Free-riding can be avoided by setting $x_{s}=\overline{\mathrm{x}}$. However, setting $\bar{x}=x_{s}$ also ensures that zero voluntary abatement is a Nash equilibrium.

PROPOSITION 6. If $x_{s}=\bar{x}$, zero voluntary abatement by all farmers $\left(a_{1 v}=0, a_{2 v}=0, \ldots, a_{n v}=0\right)$ is a Nash equilibrium. 
Proof: Let $x_{s}=\bar{x}$, and suppose $a_{-j}=(0, \ldots, 0)$. If farmer $j$ set $a_{v j}=0$, the tax will be imposed and farmer $j$ will incur a cost of $C_{j}^{*}$. Any other choice of $a_{v j}$ will yield a cost at least as high as $C_{j}^{*}$ Thus, zero abatement by all farmers is a Nash equilibrium. QED Note that when $x_{s}=\bar{x}$, the Nash equilibria include cost-minimizing abatement by all farmers and zero abatement by all farmers. Neither equilibrium involves free-riding and both lead to the outcome under which farmers meet the target at minimum cost. As a result, the cost to each farmer will be the same under the two equilibria, implying that all farmers are indifferent between them. Thus, there is no a priori reason to expect one equilibrium (for example, the equilibrium under which the target is met voluntarily) to be more likely than the other.

Figure 2 illustrates the impact of the cut-off level of pollution on the tradeoff between free-rider problems and the possibility that the environmental standard is not met voluntarily. As shown in Proposition 3, all $\left(a_{1}, a_{2}\right)$ combinations that satisfy $a_{1} \leq a_{1}^{\max }, a_{2} \leq a_{2}^{\max }$, and $x\left(a_{1}, a_{2}\right)=x_{s}$ are Nash equilibria under which the water quality standard is met voluntarily. These combinations are shown by the segment $\mathrm{AB}$ on the water quality constraint curve $x\left(a_{1}, a_{2}\right)=x_{s}$ in Figure 2a for the case where the cutoff level of pollution is set below the pollution standard. Among these combinations, only $\left(a_{1}^{*}, a_{2}^{*}\right)$ minimizes total costs, $C_{1}+C_{2}$. All other combinations imply an inefficient allocation of abatement across farmers.

With an increase in the cutoff level of pollution, the maximum abatement each farmer is willing to undertake, $a_{j}^{\max }$, decreases (see (12)). As a result, the set of Nash equilibria under which the water quality standard is met voluntarily shrinks. When the cutoff level of pollution is set equal to the pollution standard, the maximum abatement each farmer is willing to undertake 
$a_{j}^{\max }$ reduces to the cost-minimizing abatement level, the set of Nash equilibria under which the water quality standard is met voluntarily shrinks to a single (unique) point (point A in figure 2b), and the free rider problem is eliminated. Thus, in contrast to Segerson (1988) where the regulator chooses the cutoff level of pollution $\overline{\mathrm{x}}$ to ensure efficient exit/entry conditions and industry size, here the regulator can choose $\overline{\mathrm{x}}$ to eliminate or reduce the free-rider problem.

Fully eliminating the free-rider problem by setting $x_{s}=\bar{x}$ involves a trade-off, however. When $x_{s}=\bar{x}$, by Proposition 6 zero voluntary abatement is also a Nash equilibrium. As noted above, as long as $\bar{x}<x_{s}$, all Nash equilibria under which the water quality standard is met voluntarily (i.e., those located on the segment $\mathrm{AB}$ in figure $2 \mathrm{a}$ ) strictly dominate those where voluntary abatement is zero. Since the farmers pay no tax when the standard is met voluntarily, the corresponding Nash equilibria yield lower costs for all farmers than under the equilibrium where the tax is imposed. Thus the farmers collectively and individually strictly prefer to meet the standard voluntarily. However, if $x_{s}=\bar{x}$ so that the free rider problem is eliminated, the Nash equilibrium under which the target is met voluntarily no longer strictly dominates the zero voluntary abatement equilibrium, i.e., the strict preference for voluntary abatement is eliminated. Farmers now become individually and collectively indifferent between meeting the standard voluntarily and having the tax imposed, implying that success of the voluntary program is no longer a dominating equilibrium. Thus, by setting $\bar{x}<x_{s}$, the regulator increases the likelihood that the farmers will meet the target voluntarily and hence that the transaction costs associated with imposition of the tax will be avoided (as in the single farmer case), but at the cost of a decrease in allocative efficiency (i.e., an increase in the total abatement costs). 


\section{REDUCTION OF GOVERNMENT SUBSIDIES}

The analysis above assumes that the background threat takes the form of an ambient tax. However, agricultural water quality policy in the United States has historically been based on the use of "carrot" approaches designed to entice farmers to use environmentally friendly practices voluntarily through the use of government subsidies. ${ }^{16}$ Such a policy can also be used with a background threat to achieve environmental goals at minimum costs. Instead of imposing an ambient tax, the background threat could be a reduction in government subsidies if a prespecified environmental standard is not met. Specifically, under such a policy, the regulator would agree to give the farmer a chance to meet the standard voluntarily. If the standard is met, a pre-specified level of government subsidy would be paid. However, if the standard is not met voluntarily, the regulator would reduce the subsidy, with the magnitude of the reduction set at the level sufficient to induce the farmer to choose an abatement vector that ensures that the standard would be met. Formally, under the above policy, the farmer would face the following policy-related benefits:

$$
S= \begin{cases}S_{0} & \text { if } x\left(a_{v}, \theta\right) \leq x_{s} \\ S_{0}-t\left(x\left(a_{s}, \theta\right)-\bar{x}\right) & \text { if } x\left(a_{v}, \theta\right)>x_{s}\end{cases}
$$

where $S_{o}$ is the pre-specified fixed subsidy, and $a_{s}$ is the abatement level the farmer chooses when facing a threat of losing government subsidies. It can be shown that the results derived above under the assumption that the regulator threatens imposition of an ambient tax would hold as well if the regulator threatens instead to reduce government subsidies as specified above. ${ }^{17}$

\section{CONCLUSIONS}


Although the economic literature of NPP has focused on mandatory or stick approaches (e.g., input use taxes or restrictions), water quality policies in the U.S. have historically been based on the use of carrot instruments designed to entice farmers to adopt conservation practices voluntarily. Both the mandatory and voluntary approaches have been criticized in the economic literature. Mandatory approaches generally have drawbacks in terms of inflexibility or high transaction or information costs, while voluntary approaches may fail to provide adequate environmental protection. Thus, neither a purely voluntary program nor a purely mandatory approach seems to offer a desirable solution to agricultural NPP.

In this paper we examine a policy that combines a voluntary approach to controlling nonpoint-source pollution with a background threat of an ambient tax if the voluntary approach is unsuccessful in meeting a pre-specified environmental goal. In particular, we use the model to examine whether the regulator can use such a policy to induce cost-minimizing abatement decisions without the need for farm-specific information about pollution-related characteristics. We first consider how a single farmer would respond to such a combined policy, and then extend the analysis to consider multiple farmers. In the context of multiple farmers, we ask whether cost-minimizing abatement decisions are a Nash equilibrium and whether the proposed approach leads to free-riding by some farmers. We consider both a static model, in which imposition of the threat can occur instantaneously when the target is not met, and a dynamic model, in which there is a one-period lag between failure to meet the goal and imposition of the threat. While we derive the results in the context where the background threat is a tax, the results would also hold if the background threat were instead a reduction in government subsidies.

The main results can be summarized as follows. Combining a voluntary approach with a background threat of an ambient tax (or a reduction in government subsidies) can induce cost- 
minimizing abatement without the need for farm-specific information about pollution-related characteristics. This policy can therefore be both more effective than a pure voluntary approach without a threat (which might not ensure adequate environmental protection) and involve lower information or transaction costs than a pure ambient tax policy (since the regulator does not have to expend the resources to learn the site characteristics of the farm).

The ability of the policy to induce voluntary cost-minimizing abatement without the need for site-specific information holds in the context of either a single farmer or multiple farmers. In the single farmer case with an instantaneous threat, voluntary cost-minimizing abatement is an optimal response to the policy, regardless of the cutoff level of pollution. This will be the unique optimal response, when the cutoff level of pollution is set below the target level. If the threat cannot be imposed instantaneously or retroactively, then voluntary cost-minimizing abatement is still the unique optimal response provided the cutoff level is set sufficiently low, i.e., at a level that ensures that the present value of the stream of tax payments the farmer would face if the tax is imposed exceeds the one-period cost savings he would enjoy by not meeting the target voluntarily.

When the policy is applied to a group of farmers, cost-minimizing abatement is a Nash equilibrium for any choice of the cutoff level. However, with multiple farmers the voluntary cost-minimizing equilibrium is never unique. The nature of the other possible equilibria depends on the relative magnitudes of the target and cutoff levels of pollution. If the cutoff level is set less than the target level, then the combined approach will also yield Nash equilibria under which the target is met voluntarily but some farmers free ride, i.e., abate less than they would at the cost-minimizing allocation, implying an inefficient allocation of abatement across farmers. In this case, to evaluate the overall efficiency of the combined approach, the loss from free- 
riding under this approach would have to be weighed against any gain from an increase in effectiveness relative to a purely voluntary approach or against any reduction in information costs relative to a pure ambient tax policy.

It is possible to eliminate free-riding and ensure that cost-minimizing abatement is the only Nash equilibrium under which the target is met voluntarily by setting the cutoff level of pollution equal to the target level. In this case, farmers have no incentive to free ride. The potential for free riding occurs when the farmer must pay positive tax payments if the ambient tax is imposed but avoids these costs if the target is met voluntarily. This net gain (in the form of avoided tax payments) from meeting the target voluntarily makes some firms willing to abate more under voluntary compliance than they would have abated under the tax, which in turn allows other firms to abate less, i.e., to free ride. This possibility is eliminated if in equilibrium net tax payments are zero, as they would be if the target and cutoff levels of pollution are equal (since in equilibrium the target is just met). However, in this case zero voluntary abatement is also a Nash equilibrium, and the equilibrium under which the target is met voluntarily no longer strictly dominates the equilibrium under which it is not. ${ }^{18}$ When tax payments are zero in equilibrium, the farmer will incur the same total cost regardless of whether the target is met voluntarily or met as a result of imposition of the ambient tax. In either case, he incurs only the cost of abatement. Thus, while it is still possible that farmers would choose to meet the target voluntarily, they would not have a strict preference for doing so.

The above results suggest a potential efficiency tradeoff in the choice of the policy parameters when the combined policy is applied to a group of farmers. The regulator can increase the likelihood that the voluntary approach will be effective (and hence that the potential savings in information or transaction costs will be realized) by setting the cutoff level of 
pollution below the target level. The lower the cutoff level is set, the higher are the tax payments the farmer would have to make if the target is not met voluntarily. Thus, lowering the cutoff level increases the severity of the threat and hence increases the incentive for the farmer(s) to meet the target voluntarily. This holds for both the single and the multiple farmer cases.

However, when the policy is applied to a group of farmers, lowering the cutoff level has an additional effect, namely, it also increases the potential for free-riding. Although voluntary costminimizing abatement is a Nash equilibrium regardless of the cutoff level of pollution, lowering the cutoff level expands the set of Nash equilibria and hence increases the possibility that an equilibrium that is not cost-minimizing will emerge. When applied to a group of farmers, an optimal policy design would need to balance these two efficiency effects. 


\section{REFERENCES}

Babcock, Bruce, P. G. Lakshminarayan, JunJie Wu, and David Zilberman. "Public Fund For Environmental Amenities," American Journal of Agricultural Economics, Volume 78 (4) 1996: 961-971.

Batie, Sandra and David Ervin. "Flexible Incentives for Environmental Management in Agriculture: A Typology," paper presented at conference on "Flexible Incentives for the Adoption of Environmental Technologies in Agriculture," Gainesville, FL, June 1997.

Bosch, Darrell, Zena Cook, and Keith Fuglie. "Voluntary versus Mandatory Agricultural Policies to Protect Water Quality: Adoption of Nitrogen Testing in Nebraska," Review of Agricultural Economics, Volume 17 (1), 1995: 13-24.

Braden, John, and Stephen Lovejoy, eds. Water Quality and Agriculture: An International Perspective on Policies, Boulder and London: Lynne Rienner Publishers, 1990.

Braden, John, and Kathleen Segerson. "Information Problems in the Design of Nonpoint-Source Pollution," in Clifford Russell and Jason Shogren, eds., Theory, Modeling, and Experience in the Management of Nonpoint-Source Pollution, Boston: Kluwer Academic Publishers, 1993, pp. 1-35.

Cabe, Richard, and Joseph A. Herriges. 1992. "The Regulation of Non-Point-Source Pollution under Imperfect and Asymmetric Information," Journal of Environmental Economics and Management, Volume 22(2), March:134-146.

Commission of the European Communities (EC). On Environmental Agreements, Communication from the Commission to the Council and the European Parliament, Brussels, 1996.

Cooper, Joseph C., and Russ W. Keim. "Incentive Payments to Encourage Farmer Adoption of Water Quality Protection Practices," American Journal of Agricultural Economics, Volume 78 (1), February 1996: 54-64.

Dawson, $\mathrm{Na} \mathrm{Li}$, and Kathleen Segerson, "Voluntary Agreements with Industries: Participation Incentives with Industry-wide Targets," Working paper, University of Connecticut, Department of Economics, January 2002.

Govindasamy, Ramu, Joseph A. Herriges, and Jason F. Shogren. "Nonpoint Tournaments," in Cesare Dosi and Theodore Tomasi, eds., Nonpoint Source Pollution Regulation: Issues and Analysis, Dordrecht and Boston: Kluwer Academic Publishers, 1994.

Griffin, Ronald, and Daniel W. Bromley. "Agricultural Runoff as a Nonpoint Externality," American Journal of Agricultural Economics, Volume 64, 1982: 547-552. 
Hardie, Ian W., and Peter J. Parks. "Reforestation Cost-Sharing Programs," Land Economics, Volume 72, May 1996: 248-260.

Helfand, Gloria E., and Brett W. House. "Regulating Nonpoint Source Pollution Under Heterogeneous Conditions," American Journal of Agricultural Economics, Volume 77(4), November, 1995: 1024-1032.

Herriges, Joseph A., Ramu Govindasamy, and Jason F. Shogren. "Budget-Balancing Incentive Mechanisms," Journal of Environmental Economics and Management, Volume 27(3), November 1994: 275-285.

Lohr, Luanne, and Timothy Park. "Utility-Consistent Discrete-Continuous Choices in Soil Conservation," Land Economics, Volume 71 (4) November 1995: 474-490.

Norton, Nancy Anders, Tim T. Phipps, and Jerald J. Fletcher. "Role of Voluntary Programs in Agricultural Nonpoint Pollution Policy," Contemporary Economic Policy, Volume 12(1), January 1994: 113-121.

Ogg, Clayton W. and Peter J. Kuch. "Cost Sharing and Incentive Payments: The Use of Subsidies to Encourage Adoption of Environmentally Beneficial Agricultural Practices." Paper presented at conference on "Flexible Incentives for the Adoption of Environmental Technologies in Agriculture," Gainesville, FL, June 1997.

Rasmusen, Eric. 1994. Games and Information: An Introduction to Game Theory, 2nd edition. Cambridge, MA: Blackwell Publishers.

Ribaudo, Marc and Margriet Caswell. "U.S. Environmental Regulation in Agriculture and Adoption of Environmental Technology." Paper presented at conference on "Flexible Incentives for the Adoption of Environmental Technologies in Agriculture," Gainesville, FL, June 1997.

Segerson, Kathleen. "Uncertainty and Incentives for Nonpoint Pollution Control," Journal of Environmental Economics and Management, 15, 1988: 87-98.

Segerson, Kathleen and Na Li Dawson, "Enviornmental Voluntary Agreements: Participation and Free Riding," in Eric Orts and Kurt Deketelaere, eds., Environmental Contracts: Comparative Approaches to Regulatory Innovation in the United States and Europe, Kluwer Law International, 2001.

Segerson, Kathleen and Thomas J. Miceli. "Voluntary Environmental Agreements: Good or Bad News for Environmental Quality?" Journal of Environmental Economics and Management, Volume 36(2), September 1998: 109-130.

Shavell, Steven. Economic Analysis of Accident Law, Cambridge, MA: Harvard University Press, 1987. 
Shortle, James and David Abler. "Incentives for Nonpoint Pollution Control," in Cesare Dosi and Theodore Tomasi, eds., Nonpoint Source Pollution Regulation: Issues and Analysis, Dordrecht and Boston: Kluwer Academic Publishers, 1994.

Shortle, James and James Dunn. "The Relative Efficiency of Agricultural Source Water Pollution Control Policies," American Journal of Agricultural Economics, 68, 1986: 668677.

Spraggon, John. "Exogenous Targeting Instruments as a Solution to Group Moral Hazards." Journal of Public Economics 84, 2002: 427-456.

Tomasi, Theodore, Kathleen Segerson and John Braden. "Issues in the Design of Incentive Schemes for Nonpoint Source Pollution Control," in Cesare Dosi and Theodore Tomasi, eds., Nonpoint Source Pollution Regulation: Issues and Analysis, Dordrecht: Kluwer Academic Publishers, 1994, pp. 1-37.

Wiebe, Keith, Abebayehu Tegene, and Betsy Kuhn. Partial Interests in Land: Policy Tools for Resource Use and Conservation. Agricultural Economic Report Number 744, U.S. Department of Agriculture, 1996.

Wu, JunJie, and Bruce A. Babcock. "Optimal Design of a Voluntary Green Payment Program Under Asymmetric Information," Journal of Agricultural and Resource Economics, Volume 20 (2), December 1995: 316-327.

Wu, JunJie, and Bruce A. Babcock. "Purchase of Environmental Goods from Agriculture," American Journal of Agricultural Economics, Volume 78 (4) 1996: 935-945.

Wu, JunJie, and Bruce A. Babcock. "The Relative Efficiency of Voluntary vs. Mandatory Environmental Regulations," Journal of Environmental Economics and Management 37(September 1999): 158-175.

Wu, JunJie, M.L. Teague, H.P. Mapp, and D.J. Bernardo. "An Empirical Analysis of the Relative Efficiency of Policy Instruments to Reduce Nitrate Water Pollution in the U.S. Southern High Plains," Canadian Journal of Agricultural Economics 43, 1995: 403-420.

Xepapadeas, A. P. "Environmental Policy under Imperfect Information: Incentives and Moral Hazard," Journal of Environmental Economics and Management 20, 1991: 113-126.

Xepapadeas, A. P. "Environmental Policy Design and Dynamic Nonpoint-Source Pollution," Journal of Environmental Economics and Management 23, 1992: 22-39.

Xepapadeas, A. P. "Observability and Choice of Instrument Mix in the Control of Externalities," Journal of Public Economics 56(3), March 1995: 485-498. 


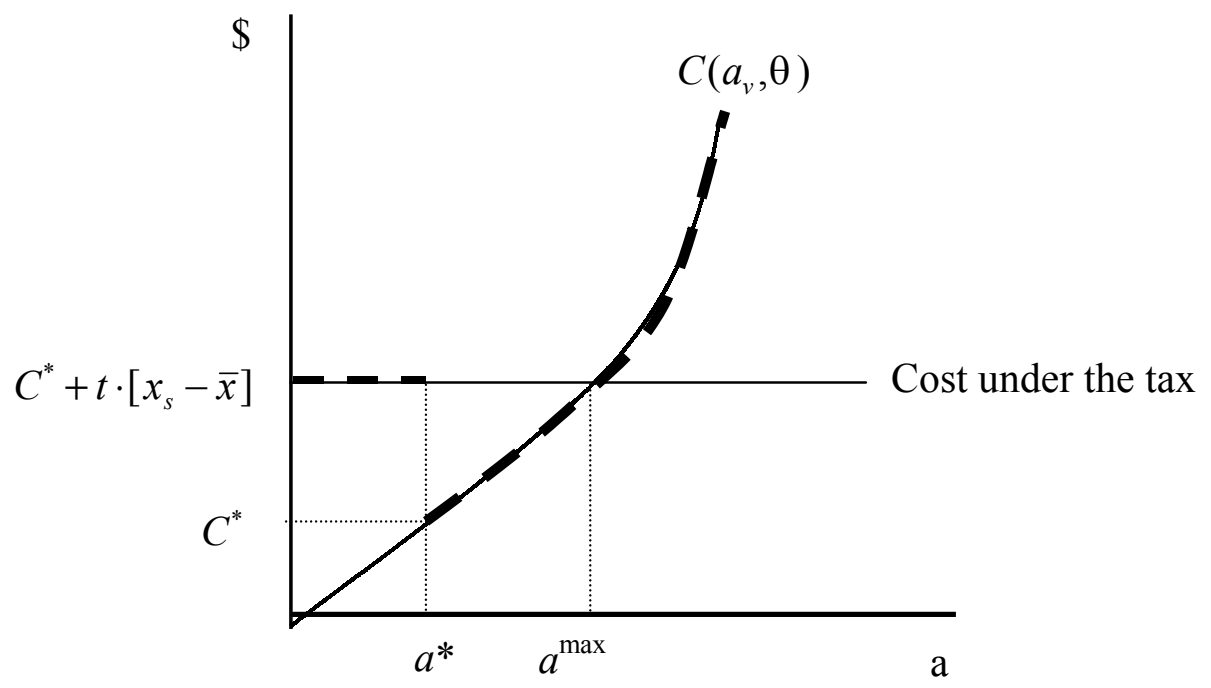

Fig. 1. Farmer's Total Cost under the Combined Policy 

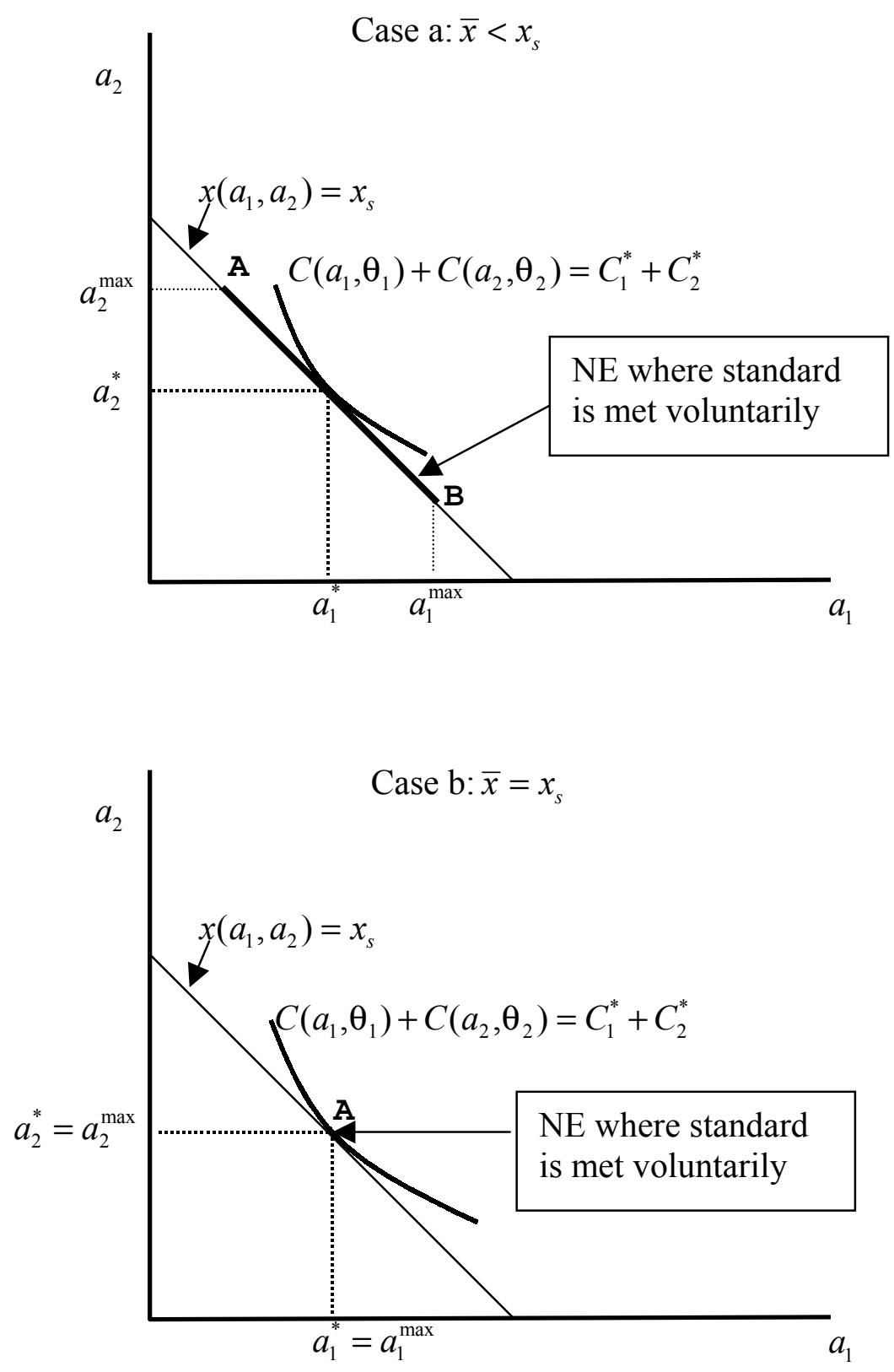

Fig. 2. The Cut-off Level of Pollution and the Tradeoff Between Creating Incentives for Voluntary Abatement and Inducing Free-Rider Problems 


\section{Footnotes}

${ }^{1}$ Recent discussions of reauthorization of the Clean Water Act, for example, have focused on the control of NPP. A notable example of nonpoint source pollution (NPP) is the contamination of surface water from the runoff of agricultural chemicals. In many locations agriculture has been identified as the largest source of NPP. Hence, much of the literature on NPP is in the context of agricultural water pollution. For an overview of issues relating to nonpoint source pollution from agriculture, see Braden and Segerson (1993) and Tomasi, Segerson and Braden (1994).

${ }^{2}$ For discussions of the use of subsidies to reduce agricultural sources of water pollution, see Braden and Lovejoy (1990), Norton et al. (1994), Lohr and Park (1995), Bosch et al. (1995), Wu and Babcock (1995), Hardie and Parks (1996), Wiebe et al. (1996), Wu and Babcock (1996), Babcock et al. (1996), Cooper and Keim (1996), Ribaudo and Caswell (1997), Ogg and Kuch (1997).

${ }^{3}$ Henceforth, we use the term "mandatory controls" to refer both to mandatory regulations or restrictions and tax-based policies such as ambient taxes or input taxes.

${ }^{4}$ It is well-recognized that actual water quality will depend on $a$ and $\theta$ as well as on other random variables such as weather (e.g., Segerson, 1988). The expected level of water quality then depends on the distribution of the weather variable. However, since we state the policy goal as one of meeting a water quality standard on average over some period rather than at every instant in time, the daily variability attributable to weather is not a key part of the analysis. Thus, for simplicity of notation, we suppress the weather variable. Note, however, that when compliance with the target is determined on a continuing basis, i.e., at every point in time, rather than on average over a period of time, the existence of weather variability affects the efficiency properties of alternative policy instruments. For example, with weather variability and continual determination of compliance, a pure ambient tax would not induce first-best abatement. See Spraggon (2002) for a useful summary.

${ }^{5}$ For some abatement practices such as installation of manure storage facilities, the abatement cost may depend on only the abatement practice.

${ }^{6}$ This is in contrast to the model in Segerson and Miceli (1998), where the level of environmental quality under the voluntary approach is determined endogenously as a result of bargaining between the regulator and the firm.

${ }^{7}$ We do not consider the case where $\bar{x}>x_{s}$, which would imply that the farmer receives net payments for meeting the standard. In this case, the farmer would never find it optimal to meet the standard voluntarily.

${ }^{8}$ It is also similar to a negligence rule in tort law, under which an injurer is liable for damages if the level of care he undertook in conducting an activity is below the "due standard of care" but not liable if he met the standard of care. See Shavell (1987) for a discussion of the economics of negligence rules.

${ }^{9}$ Given that the tax/subsidy policy in Segerson (1988) is based on actual pollution at each point in time, which fluctuates as a result of random factors such as weather, the use of the subsidy when pollution is below the target ensures efficient incentives. However, depending on the value of $\bar{x}$, it 
is possible that under the pure tax/subsidy approach, in equilibrium the farmer will choose an abatement vector such that on average the target is just met. In this case, on average no tax/subsidy payments occur in equilibrium and the equilibrium outcome under the pure tax/subsidy policy is identical to the outcome under a successful voluntary approach.

${ }^{10}$ Segerson and Miceli (1998) derive a similar conclusion in the context of their model of point source pollution. In their context, where the regulator and polluter bargain over the level of voluntary abatement, this incentive creates the possibility of "over-compliance", i.e., adoption of an abatement level that exceeds the level that would have been induced under the regulator's threat.

${ }^{11}$ This is, of course, consistent with the Folk Theorem, a well-known result from the theory of infinitely repeated games.

12 This is a reasonable assumption in a small watershed where farmers are neighbors. Our results would, however, hold even if each farmer knew only the distribution of types across the other farmers. In other words, it is not necessary for each farmer to know the types of specific farms in the watershed, but only to know the distribution of the types of farms that comprise the watershed.

${ }^{13}$ Given the assumption of an abatement index, cost minimization simply requires that abatement be allocated efficiently across farms. With an abatement vector for each farm, cost minimization would require efficient abatement allocation both across and within farms.

${ }^{14}$ See Segerson (1988). Note that since this is an ambient tax the tax rate would be the same for all farmers, even though farmers are not identical.

${ }^{15}$ A similar free rider problem arises in the model of point source pollution developed by Dawson and Segerson (2002), where the regulator threatens to impose an emissions tax on an industry if it does not meet an exogenous emissions target. As in the model here, free riding generates an inefficiency because abatement is allocated inefficiently across firms. However, Segerson and Dawson (2001) show that, despite this inefficiency, the voluntary approach will still be more efficient if the regulator threatens imposition of a costly (inefficient) regulation rather than an emissions tax. Even under the threat of a tax, the voluntary approach may still be more efficient, if the welfare loss associated with the inefficient allocation of abatement across firms is less than the information or other transaction costs required for implementation of the tax.

${ }^{16}$ See references in footnote 2 .

${ }^{17}$ Proofs are analogous and will be provided upon request.

${ }^{18}$ Zero voluntary abatement can also be a Nash equilibrium when the cutoff level is below the target level. However, in these cases the Nash equilibria with voluntary abatement strictly dominate the zero voluntary abatement equilibria. 